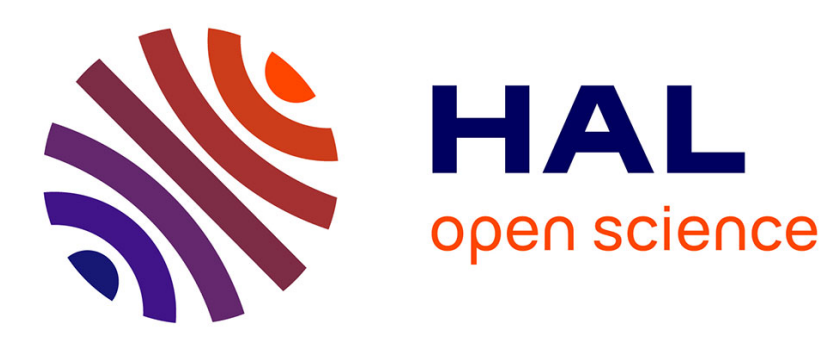

\title{
Investigations of the pulsed laser induced destruction of metals and generation of particles
}

\author{
L. Min'Ko, Yu. Chivel
}

\section{To cite this version:}

L. Min'Ko, Yu. Chivel. Investigations of the pulsed laser induced destruction of metals and generation of particles. Journal de Physique IV Proceedings, 1994, 04 (C4), pp.C4-175-C4-178. 10.1051/jp4:1994439 . jpa-00252702

HAL Id: jpa-00252702

https://hal.science/jpa-00252702

Submitted on 1 Jan 1994

HAL is a multi-disciplinary open access archive for the deposit and dissemination of scientific research documents, whether they are published or not. The documents may come from teaching and research institutions in France or abroad, or from public or private research centers.
L'archive ouverte pluridisciplinaire HAL, est destinée au dépôt et à la diffusion de documents scientifiques de niveau recherche, publiés ou non, émanant des établissements d'enseignement et de recherche français ou étrangers, des laboratoires publics ou privés. 


\title{
Investigations of the pulsed laser induced destruction of metals and generation of particles
}

\author{
L.Ya. MIN'KO and Yu.A. CHIVEL
}

Institute of Molecular and Atomic Physics, 70 F. Skaryna Av., Minsk 220602, Belarus

\section{INTRODUCTION}

Character of material destruction under the pulsed energy injection is dependent on properties of energy source, material and environmental parameters, the rate of the energy injection. At the same time, the certain resemblance is observed under the action of a different kind of a pulse energy source, manifested in the explosion - like initial destruction of a material and the appearance of a surface structures with characteristic sizes 1-10 $\mu \mathrm{m}$. Such structures where observed at both the laser irradiation (LR) action on the surface of metals [1], semiconductors [2] and at pulsed electric discharges [3]. These similarities provided reason to speculate that the non-steady-state processes in the material under the action of different pulse source are identical.

In the case of LR action surface destruction with emission of the condensed-phase particles is observed under the action of quasistationary and chaotical LR pulses $(\tau \sim \mathrm{lms})$ on absorbing materials when the evaporation threshold of the target material is exceeded [4]. Under the action of short LR pulses (10ns $1 \mu \mathrm{s})$ such effects also were registrated after the moment of plasma formation $[5,6]$. To explain the explosion - like destruction of a material the mechanisms of bulk ebullition, cavitation [7], generation of the thermal stresses [8] and shock waves [9] are used. In the present paper, a study has been made of the dynamics of interaction of monopulse LR with a metal target to elucidate the mechanism of initial destruction of a material.

\section{EXPERIMENTAL}

In our experiments, we used a neodymium Q-switched laser with a variable length (1-12 m) cavity generating monopulses of duration $40 \mathrm{~ns}$ and $300 \mathrm{~ns}$ [10]. The density distribution in the irradiation spot $2-4 \mathrm{~mm}$ in diameter was close to rectangular with inhomogeneity not worse that $20 \%$. The control over the surface state under the LR-action was carried by measurements dynamic characteristics of the mirror, diffusion, scattering components of reflected LR, surface temperature and the pressure on the target surface with a time resolution $10 \mathrm{~ns}$. To measure the luminance temperatures of the surface and plasma plum, the image of the central part of the irradiation spot was projected on the input of a photo multiplier and a high-speed photo diode. Using a photometric sphere and an auxiliary He-Ne laser, changes in the reflection coefficient of the target in the region of the irradiation spot caused by the LR were determined. For measuring the parameters of LR scattered by condensed-phase particles photo multiplier with an optical system was set at an angle of $90^{\circ}$ to the target surface normal. The scattered radiation was recorded from the $0.2 \mathrm{~mm}$ high region near the target surface, and the size of the target along the observation line exceeded the size of the irradiation spot only slightly. In the number of experiments the pressure on the target surface was measured using a piezoelectric transducer. We used flat targets made from pure aluminium A99, duralumin D16T of various degrees of purity, zinc, bismuth and ultrapure copper. The investigations were carried out in the atmospheric - pressure air and in vacuum $P \approx 10^{-2}$ Torr. The condition of the target before and after the action of LR was studied by means of ascanning electron microscope REM-100 in the regime of registration of secondary electrons. 


\section{RESULTS}

The experiments have shown that at a definite for each material threshold power density of acting LR a sharp drop is observed in the mirror component of reflected LR with a simultaneous increase in the diffusion component and the appearance of a scattering signal caused by the surge of the condensed disperse phase (CDP) (Fig.1). This is especially pronounced in the case of high-quality polished surfaces. As a rule, this effect takes place during the front edge of the LR pulse before the maximum temperature of the surface and the pressure maximum are reached (Fig.1).

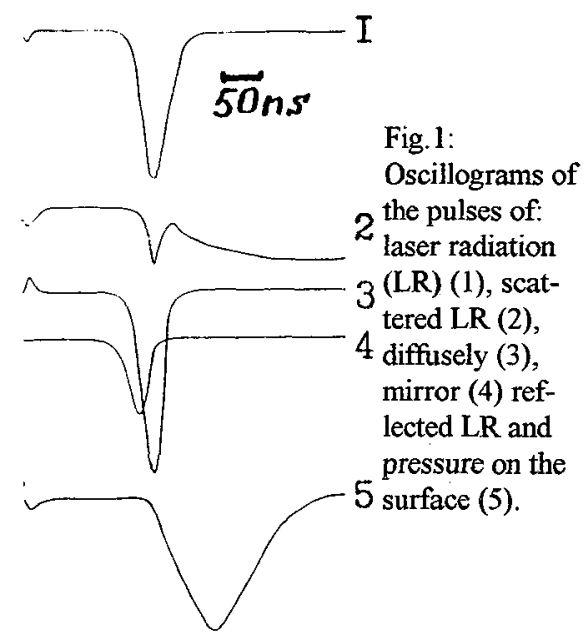

Target material - D16T, $\mathrm{q}_{\mathrm{m}}=140 \mathrm{MW} / \mathrm{cm}^{2}$ $\tau=40 \mathrm{~ns}$.

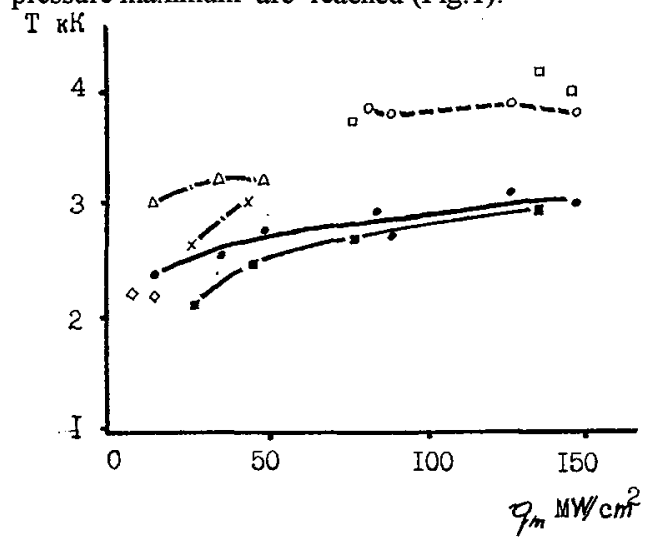

Fig.2: Target surface temperature at the moment of a sharp decrease in the mirror component of reflected LR (•-D16T, $\approx-Z n, \diamond-B i)$, maximum surface temperature $(\Delta-D 16 T, x-Z n)$, surface temperature at the moment of plasma formation (O-D16T, $\mathrm{O}$ -

$\mathrm{Zn})$ versus maximum $L R$ power density.

Such a behavior of the reflection signal is observed in both preplasma and plasma regimes of action(Fig.1). In the latter case, sudden changes in the reflective characteristics are registered before the moment of plasma formation.

Previously [11] the sharp decrease in the mirror component and the appearance of the diffusion component in reflected LR was mainly attributed to the smearing of the sharp boundary at intensive evaporation. However, as established by experiments (Fig.2), the surface temperatures registered at this moment can be both lower and higher then the evaporation temperatures of the investigated materials. To elucidate the influence of the surface condition on the reflective characteristics of the target, investigations in the preplasma regimes of irradiation were carried out. As a result, we have found, that the observable abrupt changes in the reflective characteristics of the target correlate with the appearance on the surface of microcraters, microparticles and continuity breaks with characteristics sizes $1-10 \mu \mathrm{m}$ (Fig.3). It should be noted that the above structures on the surface of materials under investigation were observed in the cases where the surface temperature threshold was exceeded in the temperature range above $2000^{\circ} \mathrm{K}$ (Fig.2).

\section{DISCUSSION}

As noted in introduction the microcraters discovered on the surface of metals were observed previously at both the LR action on the surface of metals [1, 12], semiconductors [2] and at electric discharges [3]. Their origin was associated with the material erosion at microdischarges between the intensive nearsurface plasma and surface [12], the explosion-like decay of the metastable liquid phase [13], the generation of thermal stresses $[8,14]$. Comparison of our experimental conditions with the conditions 
for the realisation of the above-mentioned mechanisms of destruction permits suggesting the presence of

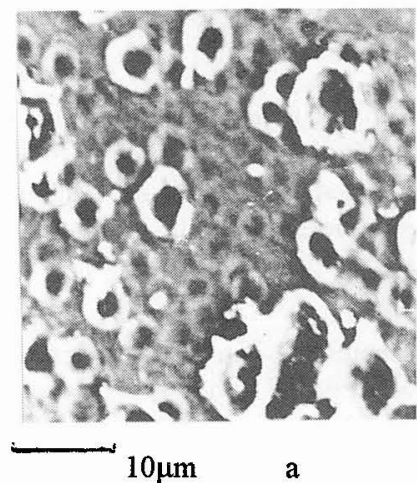

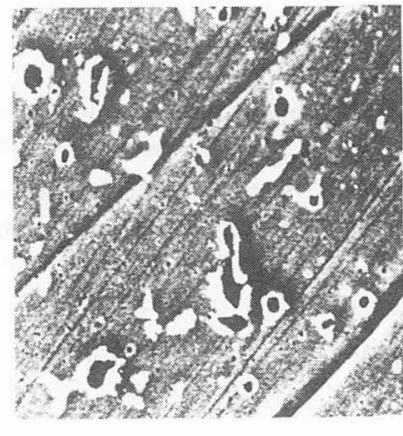

$b$

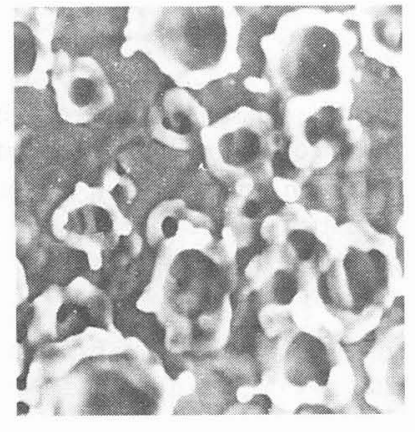

c

Fig.3. Electron-microscope photographs of the surface of an aluminium (a, b)and copper (c) target exposed to LR: $a-q_{m}=60 \mathrm{MW} / \mathrm{cm}^{2}, b-q_{m}=15 \mathrm{MW} / \mathrm{cm}^{2}, c-q_{m}=100 \mathrm{MW} / \mathrm{cm}^{2}$.

different mechanism of initial destruction of metals under the action of pulse LR. Analyses shows that the temperature threshold of plasma formation is higher than the critical temperature only for $\mathrm{Zn}$ and explosion-like boiling is possible due to the evaporation at the fluctuation centres of boiling [15]. Measurements of the pressures on the target surface have made it possible to record the onset of destruction during the period of pressure growth, which excludes cavitation whose manifestation is not excluded at the sag of the pressure pulse. The estimations of the thermoacoustic pressure which prevails in the temperature range below the boiling point in accordance with the relation [16]: $P \approx x \beta \rho \partial T / \partial t$ give the excessive pressure value $1 \mathrm{~atm}$. The destruction of metals at such low pressures is unlikely.

On the basis of the obtained results we propose a model notion of initial destruction of materials and generation of CDP particles. This notion relies on the defect deformation mechanism based on exclusively thermal action of LR and natural inhomogeneity of all solids (vacancies, pores, inclusions). As noted in [17], porosity is inherent in all solids. In particular, metals feature a pore density of $10^{8}-10^{9} \mathrm{~cm}^{-3}$ at a most probable size $0,5-2 \mu \mathrm{m}$. The authors of [18] point to the possible role of pores in the bulk boiling of materials, but is mainly attributed to the lowering of the threshold of the formation of critical bubbles at heterogeneous boiling. The influence of the gas filling the pores on the processes of destruction of materials under the laser action has not been considerate. At the same time, the authors of [19] have observed the growth of gas-filled pores in the bulk of a metal, heated by a pulsed laser to temperatures below the melting point. The calculations of heating the gases (nitrogen, hydrogen) filling a pore $0.5-1 \mu \mathrm{m}$ in size have show that it is possible to reach temperatures close to the wall temperature in times 10-100 ns. Naturally, the problem of filling the pores with a gas arises. This can be the gas originally present in the metal as well as the products of decomposition and evaporation of impurities. Moreover, the filling of pores can occur due to the desorption of the monomolecular gas layer covering the cavity walls. When the wall is heating to a temperature above $2000^{\circ} \mathrm{K}$ the time during which the gas particle remain on the surface in the case of physical absorption is $t \sim 10^{-10} \mathrm{~s}$, in the case of chemical absorption $t \sim 10^{-8} s[20]$. The estimation of the stresses arising in the thin near-surface layer of the material [21] gives values $10^{6 \div 10^{8}} \mathrm{~N} / \mathrm{m}^{2}$ close to the damage thresholds. For the case of the melted layer the dynamic of the bubble with desorption gas in thin melted layer are considered. Equation for the mechanical equilibrium of the bubble is defined as

$$
P_{e w}+\frac{2 \sigma}{R}=n \cdot k \cdot T+P_{s a t}(1)
$$

where $P_{\text {env }}, P_{\text {sat }}$ - environment and saturation vapour pressure, $\sigma$ - surface tension coefficient, $K$ Boltzman constant, $R$ - bubble radius, $T$ - gas temperature. With $T \leq T_{\text {ev }}$ (boiling temperature of the target material) $\mathrm{P}_{\mathrm{env}} \sim 10^{5} \mathrm{~Pa}, \mathrm{P}_{\text {sat }} \leq 10^{5} \mathrm{~Pa}$ and for the desorption gas $\mathrm{n}=3 \cdot \mathrm{A} / \mathrm{R}$, where $\mathrm{A}$ - surface 
gas concentration $\left(\sim 10^{15}-10^{16} \mathrm{~cm}^{-2}\right)$. By this means we obtain the expression for temperature threshold

$$
\mathrm{T} \geq \mathrm{T}^{*}=2 \sigma / 3 \mathrm{~K} \cdot \mathrm{A}(2)
$$

When the threshold is exceeded the size of the bubble with buffer gas will be enhanced independly of diameter of the bubble. The calculations point to the possibility of surface layer break with particle emission in times $\mathrm{t} \sim 10^{-8} \mathrm{~s}$. According to the calculation the particle velocity is $30-100 \mathrm{~m} / \mathrm{s}$. In the evaporation regime $\left(T \geq T_{e v}\right)$ the presence of gas in the pores will provide the pressure differential required for the licuid phase emission even in the condition of phase equilibrium on the free surface of the liquid.

Thus, we have found by experiment and confirmed by theoretical estimates the initial destruction of metals in times $t \sim 10^{-8} \mathrm{~S}$ under the action of a pulsed laser. We propose a model notion based on the defect - deformation mechanism realized at thermal heating up of an ensemble of pores in the bulk of a solid. The observed changes in the surface conditions during the laser action can significantly affect the character of the LR interaction with the target surface, which should be taken into account in calculating the damage and plasma - formation thresholds.

The observed changes in the surface condition during the laser action can significantly affect the character of the LR interaction with the target surface. The structures with a characteristic scale $10 \mu \mathrm{m}$ that have appeared on the surface can become initial inhomogeneities for the development of RayleighTaylor instability (IRT) of the liquid surface of the melt in regimes with intensive evaporation which leads, in vacuum experiments, to the formation of a large-scale relief [22]. The instability increment for the mode with $10 \mu \mathrm{m}$ will be $3 \cdot 10^{5} \mathrm{~s}^{-1}$ and the average rate of growth of the relief height at the linear stage with the initial height $1 \mu \mathrm{m}$ reaches $0.4 \mu \mathrm{m} / \mathrm{pulse}(\tau=40 \mathrm{~ns})$. On going to the non-linear regime the relief growth will be determined by the squeezing-out mechanism [22] which is due to the pressure gradient in the plasma.

\section{REFERENCES}

[1] K.Vogel, P.Backlund, 1965, J. Appl.Phys., 36, 3697 - 3701.

[2] Chechin N.G., Ditrich T., Burdel K.K., et.al., 1990, Poverhnost, 10, 76-81

[3] Yu.D.Korolev, G.A.Mesyats, 1982, Autoemission and explosion processes in gas discharge, Nauka, Moscow.

[4] Min'ko L.Ya, Loparev A.N., Nasonov V.I., Kovalev A.N., 1985, Kvant. Electron., 12, 12-16.

[5] Luchin V.I., 1980, Izv. Vuz. Radiofizika, 23, 177-180.

[6] Min'ko L.Ya., Chumakov A.N., Chivel Yu., 1983, Abstract V Conf. "Dynamics of Radiat. Gases", 2223.

[7] Zhirakov B.M., Rykalin N.N., Uglov A.A., Fannibo A.K., 1973, Kvant. Electron., 1, 119-121.

[8] Emeliyanov V.I., Kashkarov P.K., 1990, Poverhnost, 2, 77-85.

[9] Blinov V.I., Gering G.I., Eliseev N.A., 1986, Zn. Tech. Phys., 56, 2228-2231.

[10] L.Ya.Min'ko, Yu.A.Chivel, A.N. Chumakov, 1985, Zh. Prikl.Spectros., 42, 55-59.

[11] Bessarab A.V., Zhidkov N.V., Kormer S.B., et.al., 1978, Kvant.Elektron., 5, 325-330.

[12] F.Schwirske, R.J.Taylor, 1980, J. Nucl. Matter. 93/94, 780-784.

[13] Martynyuk M.M., 1980, Radiotekh.elektron, 25, 157-167.

[14] Measures R.M., 1965, Acustica, 15, 133-135.

[15] Skripov V.P., 1972, Metastable liquid, Nauka, Moscow.

[16] Samokhin A.A., 1988, Proc. IOFAN, 13, 3-98.

[17] CheremskoyP.G., Sizov V.V., Betekhtin V.I., 1990, Pores in solids, Energjatomizdat, Moscow.

[18] Rykalin N.N., Uglov A.A., 1970, Fiz. khim. obrab. mater., 2, 33-36.

[19] Chaplanov A.M., Tochitsky E.L., 1984, Thin Solid Films, 116, 117-128.

[20] Groshkovsky J., 1972, High Vacuum Technology, WNT, Warszawa.

[21] Landau L.R., Lifshits E.M., 1978, Theory of elastisity, Fizmatgiz, Moscow.

[22] Yu.A.Chivel, 1991, Kvant. Electron, 18, 1218-1222 